Research

Open Access

\title{
Increasing arterial blood pressure with norepinephrine does not improve microcirculatory blood flow: a prospective study
}

\author{
Arnaldo Dubin ${ }^{1,2}$, Mario O Pozo ${ }^{3}$, Christian A Casabella ${ }^{1}$, Fernando Pálizas Jr ${ }^{3}$, Gastón Murias ${ }^{3}$, \\ Miriam C Moseinco ${ }^{1}$, Vanina S Kanoore Edul11,2, Fernando Pálizas ${ }^{3}$, Elisa Estenssoro ${ }^{4}$ and \\ Can Ince 5
}

\author{
1Servicio de Terapia Intensiva, Sanatorio Otamendi y Miroli, Azcuénaga 870, Buenos Aires C1115AAB, Argentina \\ ${ }^{2}$ Cátedra de Farmacología Aplicada, Facultad de Ciencias Médicas, Universidad Nacional de La Plata, 60 y 120, La Plata 1900, Argentina \\ ${ }^{3}$ Servicio de Terapia Intensiva, Clínica Bazterrica, Juncal 3002, Buenos Aires C1425AYN, Argentina \\ ${ }^{4}$ Servicio de Terapia Intensiva, Hospital San Martín, 1 y 70, La Plata 1900, Argentina \\ 5Translational Physiology, Academic Medical Center, University of Amsterdam, Meibergdreef 9, Amsterdam 1105 AZ, The Netherlands
}

Corresponding author: Arnaldo Dubin, arnaldodubin@speedy.com.ar

Received: 5 May 2009 Revisions requested: 18 May 2009 Revisions received: 25 May 2009 Accepted: 17 Jun 2009 Published: 17 Jun 2009

Critical Care 2009, 13:R92 (doi:10.1186/cc7922)

This article is online at: http://ccforum.com/content/13/3/R92

(c) 2009 Dubin et al:; licensee BioMed Central Ltd.

This is an open access article distributed under the terms of the Creative Commons Attribution License (http://creativecommons.org/licenses/by/2.0), which permits unrestricted use, distribution, and reproduction in any medium, provided the original work is properly cited.

\begin{abstract}
Introduction Our goal was to assess the effects of titration of a norepinephrine infusion to increasing levels of mean arterial pressure (MAP) on sublingual microcirculation.

Methods Twenty septic shock patients were prospectively studied in two teaching intensive care units. The patients were mechanically ventilated and required norepinephrine to maintain a mean arterial pressure (MAP) of $65 \mathrm{mmHg}$. We measured systemic hemodynamics, oxygen transport and consumption $\left(\mathrm{DO}_{2}\right.$ and $\left.\mathrm{VO}_{2}\right)$, lactate, albumin-corrected anion gap, and gastric intramucosal-arterial $\mathrm{PCO}_{2}$ difference $\left(\Delta \mathrm{PCO}_{2}\right)$. Sublingual microcirculation was evaluated by sidestream darkfield (SDF) imaging. After basal measurements at a MAP of $65 \mathrm{mmHg}$, norepinephrine was titrated to reach a MAP of 75 $\mathrm{mmHg}$, and then to $85 \mathrm{mmHg}$. Data were analyzed using repeated measurements ANOVA and Dunnett test. Linear trends between the different variables and increasing levels of MAP were calculated.

Results Increasing doses of norepinephrine reached the target values of MAP. The cardiac index, pulmonary pressures,

systemic vascular resistance, and left and right ventricular stroke work indexes increased as norepinephrine infusion was augmented. Heart rate, $\mathrm{DO}_{2}$ and $\mathrm{VO}_{2}$, lactate, albumincorrected anion gap, and $\triangle \mathrm{PCO}_{2}$ remained unchanged. There were no changes in sublingual capillary microvascular flow index $(2.1 \pm 0.7,2.2 \pm 0.7,2.0 \pm 0.8)$ and the percent of perfused capillaries $(72 \pm 26,71 \pm 27,67 \pm 32 \%)$ for MAP values of 65 , 75 , and $85 \mathrm{mmHg}$, respectively. There was, however, a trend to decreased capillary perfused density $(18 \pm 10,17 \pm 10,14 \pm 2$ vessels $/ \mathrm{mm}^{2}$, respectively, ANOVA $P=0.09$, linear trend $P=$ $0.045)$. In addition, the changes of perfused capillary density at increasing MAP were inversely correlated with the basal perfused capillary density $\left(R^{2}=0.95, P<0.0001\right)$.

Conclusions Patients with septic shock showed severe sublingual microcirculatory alterations that failed to improve with the increases in MAP with norepinephrine. Nevertheless, there was a considerable interindividual variation. Our results suggest that the increase in MAP above $65 \mathrm{mmHg}$ is not an adequate approach to improve microcirculatory perfusion and might be harmful in some patients.
\end{abstract}

\section{Introduction}

Septic shock is characterized by severe vasodilation and hypotension refractory to aggressive fluid resuscitation [1]. Despite the normalization of cardiac output, evidence of tissue hypoperfusion is frequently present. Accordingly, organ dysfunctions usually develop despite normal or increased oxygen transport $\left(\mathrm{DO}_{2}\right)$. Microcirculatory alterations could be an underlying explanation for these findings [2]. Experimental models of resuscitated septic shock show that microvascular perfusion is altered despite the normalization of systemic and regional hemodynamics [3]. In addition, septic patients systematically exhibit severe disorders in sublingual microcircula-

ANOVA: analysis of variance; $\mathrm{DO}_{2}$ : oxygen transport; MAP: mean arterial pressure; MFI: microvascular flow index; $\mathrm{PCO}_{2}:$ partial pressure of carbon dioxide; $\triangle \mathrm{PCO}_{2}$ : gastric intramucosal-arterial $\mathrm{PCO}_{2}$ difference; $\mathrm{PO}_{2}$ : partial pressure of oxygen; SDF: sidestream darkfield. 
tion that are strongly associated with organ failures and outcome $[4,5]$. The ability to improve sublingual microcirculation has also been related to survival [5]. Moreover, sublingual perfusion might be enhanced by different therapeutic strategies that include the use of vasoactive drugs $[6,7]$. In this way, improving microcirculation might be an important goal in the resuscitation of patients with septic shock.

An approach to improve microcirculation is to increase the perfusion pressure. When the mean arterial pressure (MAP) decreases below an autoregulatory threshold of about 60 to $65 \mathrm{mmHg}$, organ perfusion becomes pressure dependent [8]. Nevertheless, intravascular thrombosis and vasoconstrictor mediators, along with regional deficiencies in nitric oxide production, could alter vascular reactivity and shift the autoregulatory threshold to higher values $[9,10]$. Consequently, the increase in MAP could improve tissue perfusion. Clinical studies, however, have shown that the elevation in MAP beyond 65 $\mathrm{mmHg}$ fails to increase systemic oxygen metabolism, skin microcirculatory blood flow, urine output, splanchnic perfusion, or renal function $[11,12]$. The experimental evidence regarding this issue, however, is controversial [13-17].

Our goal was to assess the effects of titration of a norepinephrine infusion to increasing levels of MAP on sublingual microcirculation. We hypothesized that the increase in MAP from 65 to $75 \mathrm{mmHg}$, and then to $85 \mathrm{mmHg}$ does not improve sublingual microcirculatory blood flow. At the time of submission of this manuscript, a very similar study was published [18], which reported that escalating doses of norepinephrine in septic patients increased $\mathrm{DO}_{2}$ and tissue oxygenation, and were not associated with significant changes in preexisting sublingual microvascular alterations. The results of our study confirm these previous findings, but suggest that the individual responses are related to the basal microcirculatory condition.

\section{Materials and methods}

The protocol was approved by the Institutional Review Boards of Sanatorio Otamendi and Clínica Bazterrica. Informed consent was obtained from the next of kin of all patients admitted to the study.

\section{Setting}

This study was conducted in two teaching intensive care units.

\section{Patients}

The study population included 20 septic shock patients [19] requiring norepinephrine despite adequate fluid resuscitation to maintain a MAP of $65 \mathrm{mmHg}$ or higher (Table 1). They were mechanically ventilated in controlled mode and received infusions of midazolam and fentanyl. All patients had a systemic arterial catheter and a pulmonary artery catheter inserted. A tonometric nasogastric tube was placed into the stomach (TRIP NGS Catheter, Tonometrics, Worcester, MA, USA), after which radiographic confirmation of catheter position was
Table 1

Clinical and epidemiological characteristics of the patients

$\begin{array}{lc}\text { Age, years } & 72 \pm 12 \\ \text { Gender, \% male } & 55 \\ \text { SOFA score } & 9.8 \pm 2.8 \\ \text { APACHE II score } & 24.4 \pm 5.4 \\ \text { APACHE II predicted risk mortality } & 50.8 \pm 17.5 \\ \text { Actual mortality, \% } & 50 \\ \text { Source of sepsis, } \mathbf{n}(\%) & \\ \quad \text { Pneumonia } & 9(45) \\ \quad \text { Intra-abdominal infection } & 3(15) \\ \quad \text { Primary bacteremia } & 3(15) \\ \quad \text { Endovascular infection } & 2(10) \\ \quad \text { Cellulitis } & 2(10) \\ \quad \text { Urinary tract infection } & 1(5) \\ \text { Fluid balance on the previous day, } \mathrm{ml} & 4592 \pm 3156 \\ \text { Fluid administration on the previous day, } \mathrm{ml} & 6183 \pm 2601\end{array}$

APACHE $=$ Acute Physiology and Chronic Health Evaluation; SOFA $=$ Sepsis-related Organ Failure Assessment.

obtained. All patients received intravenous ranitidine. The clinical characteristics of the patients are presented in Table 1.

\section{Measurements and derived calculations}

Serial measurements of heart rate, MAP, mean arterial pulmonary pressure, pulmonary artery occlusion pressure, and central venous pressure were performed. Transducers were referenced to the midaxillary line and all pressures were taken at end-expiration. Cardiac output was measured by thermodilution using three injections of saline solution $(10 \mathrm{cc})$ at room temperature.

Arterial, mixed venous, and central venous blood samples were analyzed for gases, hemoglobin, and oxygen saturation (AVL OMNI 9, Roche Diagnostics, Graz, Austria). Sodium $(\mathrm{Na})$, potassium $(\mathrm{K})$ and chloride $(\mathrm{Cl})$ ions (selective electrode ion, AEROSET, Abbott Laboratories, Abbott Park, IL, USA), albumin (Bromcresol-sulfonphthaleinyl), and lactate (selective electrode ion, AVL OMNI 9) were measured in arterial blood samples. The albumin-corrected anion gap was calculated [20] as:

$[\mathrm{AG}]_{\text {corrected }}(\mathrm{mmol} / \mathrm{L})=\left(\left[\mathrm{Na}^{+}\right]+\left[\mathrm{K}^{+}\right]\right)-\left(\left[\mathrm{Cl}^{-}\right]+\left[\mathrm{HCO}_{3}^{-}\right]\right)+0.25 *([$ normal albumin $]-$ [observed albumin]) (in $\mathrm{g} / \mathrm{L}$ ).

Derived hemodynamic and $\mathrm{DO}_{2}$ variables were calculated according to standard formulae.

Intramucosal partial pressure of carbon dioxide $\left(\mathrm{PCO}_{2}\right)$ was measured with a tonometer using an automated air tonometry system (Tonocap; Datex Ohmeda, Helsinki, Finland). Its value 
was used to calculate the intramucosal-arterial $\mathrm{PCO}_{2}$ difference $\left(\triangle \mathrm{PCO}_{2}\right)$.

\section{Microvideoscopic measurements and analysis}

The microcirculatory network was evaluated in the sublingual mucosa using a sidestream dark field (SDF) imaging device (Microscan ${ }^{\circledR}$, MicroVision Medical, Amsterdam, Netherlands) [21].

Different cautions and steps were followed to obtain images of adequate quality and to ensure good reproducibility. Video acquisition and image analyses were performed by welltrained researchers (AD, MOP and VSKE). After gentle removal of saliva by isotonic-saline-drenched gauze, steady images of at least 20 seconds were obtained while avoiding pressure artifacts using a portable computer and an analog/ digital video converter (ADVC110, Canopus Co, San Jose, CA, USA). Video clips were stored as AVI files to allow computerized frame-by-frame image analysis. SDF images were acquired from at least five different sites. Adequate focus and contrast adjustment were verified, and images of poor quality were discarded. The entire sequence was used to characterize the semi-quantitative characteristics of microvascular blood flow, particularly the presence of stopped or intermittent flow.

Video clips were analyzed blindly and randomly using different approaches. First, we used a previously validated semi-quantitative score [22]. It distinguishes between no flow (0), intermittent flow (1), sluggish flow (2), and continuous flow (3) [22]. A value was assigned to each individual vessel. The overall score, called the microvascular flow index (MFI), is the average of the individual values. For each patient, the values from five to eight videos were averaged. In addition, vascular density was quantified as the number of vessels per $\mathrm{mm}^{2}$. To determine heterogeneity of perfusion in each territory, the flow heterogeneity index was calculated as the highest MFI minus the lowest MFI divided by the mean MFI [23]. These quantifications of flow were made per group of vessel diameter: small (capillaries), 10 to $20 \mu \mathrm{m}$; medium, 21 to $50 \mu \mathrm{m}$; and large, 51 to $100 \mu \mathrm{m}$. Finally, the percentage of perfused vessels and the total and capillary perfused vascular densities were calculated $[4,24]$. The percentage of perfused vessels was calculated as the number of vessels with flow 2 and 3 divided by the total number of vessels multiplied by 100 .

\section{Study protocol}

After fluid resuscitation failed to improve MAP, a norepinephrine infusion was adjusted to reach a MAP of $65 \mathrm{mmHg}$ in all patients. After a period of at least two hours in which the requirement of norepinephrine to maintain a MAP of $65 \mathrm{mmHg}$ remained unchanged, the measurements were performed. Norepinephrine was then titrated to reach a MAP of $75 \mathrm{mmHg}$. After 30 minutes at this MAP, new measurements were taken. Finally, norepinephrine infusion was increased to achieve a MAP of $85 \mathrm{mmHg}$ and, after 30 minutes at this MAP, a final set of measurements were taken.

No additional sedation, antipyretics or vasoactive drugs were administered during the study period. The infusions of midazolam and fentanyl were kept constant at rates of $0.99 \pm 0.22$ $\mathrm{mg} / \mathrm{kg} / \mathrm{hour}$ and $0.82 \pm 0.20 \mu \mathrm{g} / \mathrm{kg} /$ hour, respectively.

\section{Analysis of data}

After showing a normal distribution, data were analyzed using repeated measurements analysis of variance (ANOVA) and

Table 2

Changes in hemodynamic, oxygen transport, and tonometric variables as mean arterial pressure was increased from $65 \mathrm{mmHg}$ to 85 mmHg with norepinephrine

\begin{tabular}{|c|c|c|c|c|c|}
\hline & \multicolumn{3}{|c|}{ Mean arterial blood pressure } & \multirow{2}{*}{$\begin{array}{c}\text { ANOVA } \\
P\end{array}$} & \multirow{2}{*}{$\begin{array}{c}\text { Linear trend } \\
P\end{array}$} \\
\hline & $65 \mathrm{mmHg}$ & $75 \mathrm{mmHg}$ & $85 \mathrm{mmHg}$ & & \\
\hline Norepinephrine doses $(\mu \mathrm{g} / \mathrm{kg} / \mathrm{min})$ & $0.48 \pm 0.43$ & $0.65 \pm 0.68^{\star}$ & $0.74 \pm 0.67^{\star}$ & $<0.0001$ & $<0.0001$ \\
\hline Heart rate (beats/min) & $94 \pm 21$ & $92 \pm 18$ & $93 \pm 18$ & 0.59 & 0.43 \\
\hline Mean arterial blood pressure $(\mathrm{mmHg})$ & $65 \pm 2$ & $76 \pm 2^{*}$ & $85 \pm 2^{\star}$ & $<0.0001$ & $<0.0001$ \\
\hline Mean pulmonary artery pressure $(\mathrm{mmHg})$ & $28 \pm 7$ & $30 \pm 7^{*}$ & $30 \pm 7^{\star}$ & $<0.0001$ & $<0.0001$ \\
\hline Pulmonary artery occlusion pressure $(\mathrm{mmHg})$ & $14 \pm 4$ & $15 \pm 4$ & $16 \pm 4$ & 0.06 & 0.02 \\
\hline Central venous pressure $(\mathrm{mmHg})$ & $11 \pm 4$ & $12 \pm 4$ & $12 \pm 4$ & 0.18 & 0.47 \\
\hline Cardiac index $\left(1 / \mathrm{min} / \mathrm{m}^{2}\right)$ & $2.98 \pm 0.99$ & $3.11 \pm 1.07$ & $3.23 \pm 1.02^{\star}$ & 0.0002 & $<0.0001$ \\
\hline Oxygen transport $\left(\mathrm{ml} / \mathrm{min} / \mathrm{m}^{2}\right)$ & $366 \pm 137$ & $379 \pm 145$ & $383 \pm 166$ & 0.53 & 0.28 \\
\hline Oxygen consumption $\left(\mathrm{ml} / \mathrm{min} / \mathrm{m}^{2}\right)$ & $100 \pm 33$ & $91 \pm 31$ & $90 \pm 40$ & 0.61 & 0.63 \\
\hline Intramucosal-arterial $\mathrm{pCO}_{2}(\mathrm{mmHg})$ & $15 \pm 15$ & $16 \pm 18^{*}$ & $16 \pm 18$ & 0.03 & 0.06 \\
\hline
\end{tabular}

* $P<0.05$ vs. basal (Dunnett post hoc test after repeated measures ANOVA).

ANOVA $=$ analysis of variance; $\mathrm{pCO}_{2}=$ partial pressure of carbon dioxide. 
Dunnett test. Linear trends between the different variables and increasing levels of MAP were calculated [25]. A $P<0.05$ was considered significant. Data are showing as mean \pm standard deviation.

\section{Results}

Effects on hemodynamic and oxygen transport variables Increasing doses of norepinephrine induced the target values of MAP. Cardiac index and pulmonary pressures increased as norepinephrine infusion was augmented. Heart rate, $\mathrm{DO}_{2}$ and oxygen consumption remained unchanged (Table 2).

\section{Effects on lactate and acid-base parameters}

Arterial lactate levels were stable. Venous oxygen saturations and pressures increased while other acid-base variables were unmodified (Table 3).

\section{Effects on gastric tonometry}

$\triangle \mathrm{PCO}_{2}$ did not change throughout the study (Table 2).

\section{Effects on sublingual microcirculation}

Although the total vascular density was not significantly altered, there was a trend to a decreased capillary density (ANOVA $P=0.09$, linear trend $P=0.03$; Table 4). The MFI and the percentage of perfused vessels were unchanged in the different types of vessels at increasing MAP values. The total perfused vascular density was unmodified for MAP values of 65,75 , and $85 \mathrm{mmHg}(38 \pm 14,37 \pm 15,37 \pm 4$ vessels/ $\mathrm{mm}^{2}$, respectively, ANOVA $P=0.94$, linear trend $P=0.76$ ); however, there was a trend to a decreased perfused capillary density $\left(18 \pm 10,17 \pm 10,14 \pm 2\right.$ vessels $/ \mathrm{mm}^{2}$, respectively, ANOVA $P=0.09$, linear trend $P=0.045)$. The heterogeneity flow index also remained unchanged (Table 4). The individual behaviour of capillary density, capillary MFI, percentage of perfused capillaries, perfused capillary density and capillary heterogeneity flow index are depicted in Figures 1 to 5 . There was, however, considerable interindividual variability. In particular, there was a strong linear relationship between the changes of perfused capillary density, when MAP was increased from baseline to $85 \mathrm{mmHg}$, with the basal perfused capillary density at a MAP of $65 \mathrm{mmHg}$ (Figure 6).

\section{Discussion}

The main finding of this study is that the increase in MAP with norepinephrine failed to improve sublingual microcirculation, or any other variable related to perfusion as arterial lactate, anion gap, $\triangle \mathrm{PCO}_{2}$, and parameters of oxygen metabolism. Despite a trend to decreased total and perfused capillary density, there were considerable variations in the interindividual responses that seem to depend on the basal condition of the microcirculation.

The goal of vasopressor therapy is to improve tissue perfusion pressure, while avoiding excessive vasoconstriction. Marik and Mohedin showed that an infusion of norepinephrine titrated to increase the MAP to more than $75 \mathrm{mmHg}$ improved intramucosal pH [26]. Martin and colleagues [27] and Desjars and colleagues [28] reported significant increases in urine output

\section{Table 3}

Changes in arterial lactate, hemoglobin, blood gases and oxygen saturations as mean arterial pressure was increased from 65 $\mathrm{mmHg}$ to $85 \mathrm{mmHg}$ with norepinephrine

\begin{tabular}{|c|c|c|c|c|c|}
\hline & \multicolumn{3}{|c|}{ Mean arterial blood pressure } & \multirow{2}{*}{$\begin{array}{c}\text { ANOVA } \\
P\end{array}$} & \multirow{2}{*}{$\begin{array}{c}\text { Linear trend } \\
P\end{array}$} \\
\hline & $65 \mathrm{mmHg}$ & $75 \mathrm{mmHg}$ & $85 \mathrm{mmHg}$ & & \\
\hline Arterial lactate $(\mathrm{mmol} / \mathrm{L})$ & $2.6 \pm 2.8$ & $2.4 \pm 2.7$ & $2.5 \pm 2.7$ & 0.27 & 0.32 \\
\hline Hemoglobin (g\%) & $9.6 \pm 2.3$ & $9.6 \pm 2.4$ & $9.6 \pm 2.3$ & 0.76 & 0.79 \\
\hline Arterial pH & $7.26 \pm 0.11$ & $7.26 \pm 0.11$ & $7.26 \pm 0.11$ & 0.44 & 0.29 \\
\hline Arterial $\mathrm{PCO}_{2}(\mathrm{mmHg})$ & $39 \pm 10$ & $39 \pm 10$ & $40 \pm 11$ & 0.73 & 0.57 \\
\hline Arterial $\mathrm{PO}_{2}(\mathrm{mmHg})$ & $112 \pm 48$ & $113 \pm 45$ & $108 \pm 34$ & 0.39 & 0.25 \\
\hline Arterial $\mathrm{HCO}_{3}^{-}(\mathrm{mmol} / \mathrm{l})$ & $18 \pm 5$ & $18 \pm 5$ & $18 \pm 5$ & 0.50 & 0.43 \\
\hline Arterial oxygen saturation & $0.96 \pm 0.02$ & $0.96 \pm 0.02$ & $0.96 \pm 0.03$ & 0.67 & 0.44 \\
\hline Mixed venous $\mathrm{pH}$ & $7.23 \pm 0.11$ & $7.24 \pm 0.10$ & $7.24 \pm 0.10$ & 0.78 & 0.49 \\
\hline Mixed venous $\mathrm{PCO}_{2}(\mathrm{mmHg})$ & $45 \pm 11$ & $45 \pm 11$ & $45 \pm 11$ & 0.90 & 0.69 \\
\hline Mixed venous $\mathrm{PO}_{2}(\mathrm{mmHg})$ & $42 \pm 7$ & $43 \pm 7$ & $44 \pm 8^{*}$ & 0.04 & 0.02 \\
\hline Mixed venous $\mathrm{HCO}_{3}{ }^{-}(\mathrm{mmol} / \mathrm{l})$ & $19 \pm 5$ & $19 \pm 5$ & $19 \pm 5$ & 0.18 & 0.08 \\
\hline Mixed venous oxygen saturation & $0.70 \pm 0.08$ & $0.72 \pm 0.08^{*}$ & $0.73 \pm 0.07^{*}$ & 0.01 & 0.005 \\
\hline Central venous oxygen saturation & $0.74 \pm 0.08$ & $0.76 \pm 0.08^{*}$ & $0.77 \pm 0.08^{*}$ & 0.01 & 0.004 \\
\hline Arterial anion gap (mmol/L) & $18 \pm 6$ & $19 \pm 6$ & $20 \pm 7$ & 0.16 & 0.06 \\
\hline
\end{tabular}

* $P<0.05$ vs. basal (Dunnett post hoc test after repeated measures ANOVA).

ANOVA $=$ analysis of variance; $\mathrm{HCO}_{3}=$ bicarbonate; $\mathrm{pCO}_{2}=$ partial pressure of carbon dioxide; $\mathrm{pO}_{2}=\mathrm{partial}$ pressure of oxygen. 


\begin{tabular}{|c|c|c|c|c|c|}
\hline & \multicolumn{3}{|c|}{ Mean arterial blood pressure } & \multirow{2}{*}{$\begin{array}{c}\text { ANOVA } \\
P\end{array}$} & \multirow{2}{*}{$\begin{array}{c}\text { Linear treno } \\
\text { P }\end{array}$} \\
\hline & $65 \mathrm{mmHg}$ & $75 \mathrm{mmHg}$ & $85 \mathrm{mmHg}$ & & \\
\hline \multicolumn{6}{|l|}{ Vascular density (vessels $/ \mathrm{mm}^{2}$ ) } \\
\hline Large diameter vessels & $11 \pm 1$ & $10 \pm 3$ & $10 \pm 3$ & 0.81 & 0.61 \\
\hline Medium diameter vessels & $15 \pm 3$ & $16 \pm 4$ & $16 \pm 4$ & 0.82 & 0.53 \\
\hline Small diameter vessels & $24 \pm 8$ & $23 \pm 8$ & $22 \pm 1$ & 0.09 & 0.03 \\
\hline \multicolumn{6}{|l|}{ Microvascular flow index } \\
\hline Large diameter vessels & $2.3 \pm 0.6$ & $2.3 \pm 0.8$ & $2.2 \pm 0.8$ & 0.34 & 0.16 \\
\hline Medium diameter vessels & $2.2 \pm 0.7$ & $2.2 \pm 0.7$ & $2.1 \pm 0.9$ & 0.79 & 0.52 \\
\hline Small diameter vessels & $2.1 \pm 0.7$ & $2.2 \pm 0.7$ & $2.0 \pm 0.8$ & 0.69 & 0.47 \\
\hline \multicolumn{6}{|l|}{ Perfused vessels (\%) } \\
\hline Large diameter vessels & $82 \pm 21$ & $80 \pm 28$ & $87 \pm 6$ & 0.46 & 0.40 \\
\hline Medium diameter vessels & $77 \pm 27$ & $77 \pm 29$ & $77 \pm 6$ & 0.98 & 1.00 \\
\hline Small diameter vessels & $72 \pm 26$ & $71 \pm 27$ & $67 \pm 32$ & 0.55 & 0.38 \\
\hline Total vessels & $75 \pm 25$ & $75 \pm 27$ & $76 \pm 4$ & 0.92 & 0.73 \\
\hline \multicolumn{6}{|l|}{ Heterogeneity flow index } \\
\hline Large diameter vessels & $1.0 \pm 0.5$ & $1.3 \pm 1.2$ & $1.5 \pm 1.4$ & 0.07 & 0.02 \\
\hline Medium diameter vessels & $1.6 \pm 1.6$ & $1.5 \pm 1.4$ & $1.7 \pm 1.2$ & 0.86 & 0.78 \\
\hline Small diameter vessels & $1.8 \pm 1.3$ & $1.8 \pm 1.2$ & $1.7 \pm 1.1$ & 0.97 & 0.80 \\
\hline
\end{tabular}

ANOVA $=$ analysis of variance.

and improvements in renal function in septic shock. Nevertheless, in these studies [26-28] the initial MAP was below 60 $\mathrm{mmHg}$, a value that is most likely beyond the lower limit of autoregulation. On the other hand, Deruddre and colleagues showed that increasing MAP from 65 to $75 \mathrm{mmHg}$ with norepinephrine in patients with septic shock increased urinary output and decreased renal vascular resistance [29].

Figure 1

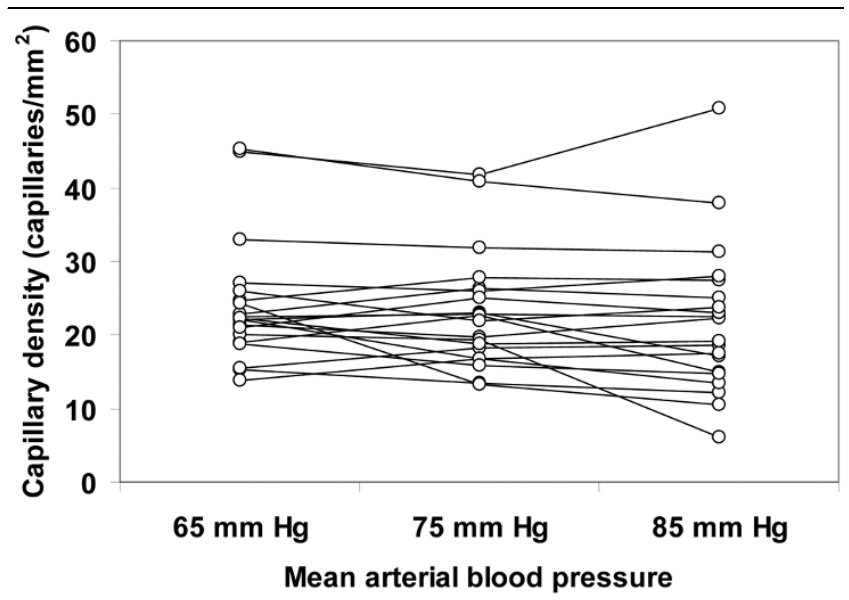

Individual behavior of the sublingual capillary density. Results are shown as the mean arterial pressure was increased from $65 \mathrm{mmHg}$ to $85 \mathrm{mmHg}$ with norepinephrine.
Our study is consistent with the results from LeDoux and colleagues [11] and Bourgoin and colleagues [12]. In these studies, the lack of change in any perfusion variable over a range of $20 \mathrm{mmHg}$ in MAP suggests that the patients were within their autoregulatory range. Jhanji and colleagues have recently demonstrated that increasing doses of norepinephrine resulted in an increase in global $\mathrm{DO}_{2}$, and in cutaneous micro-

Figure 2

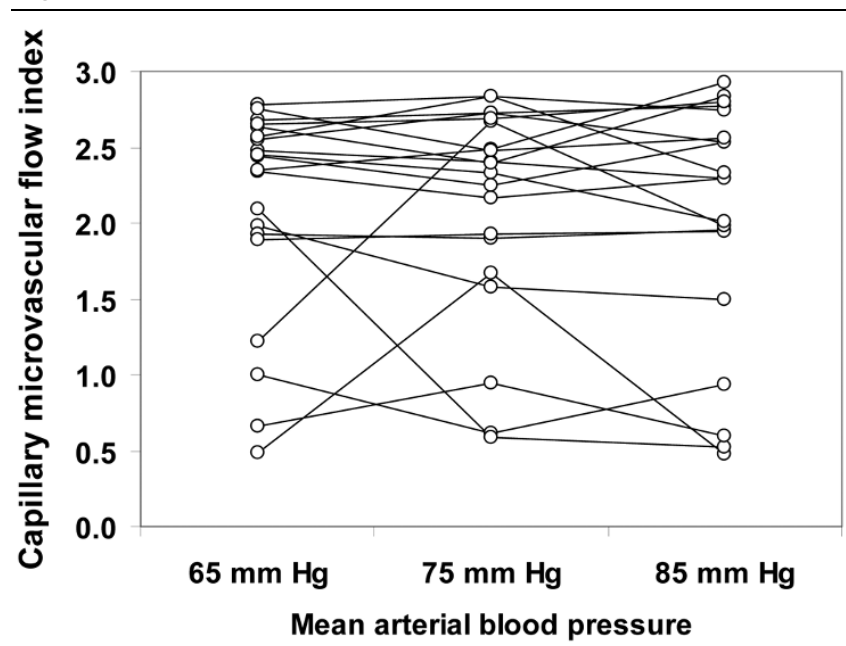

Individual behavior of sublingual capillary microvascular flow index. Results are shown as the mean arterial pressure was increased from $65 \mathrm{mmHg}$ to $85 \mathrm{mmHg}$ with norepinephrine. 
Figure 3

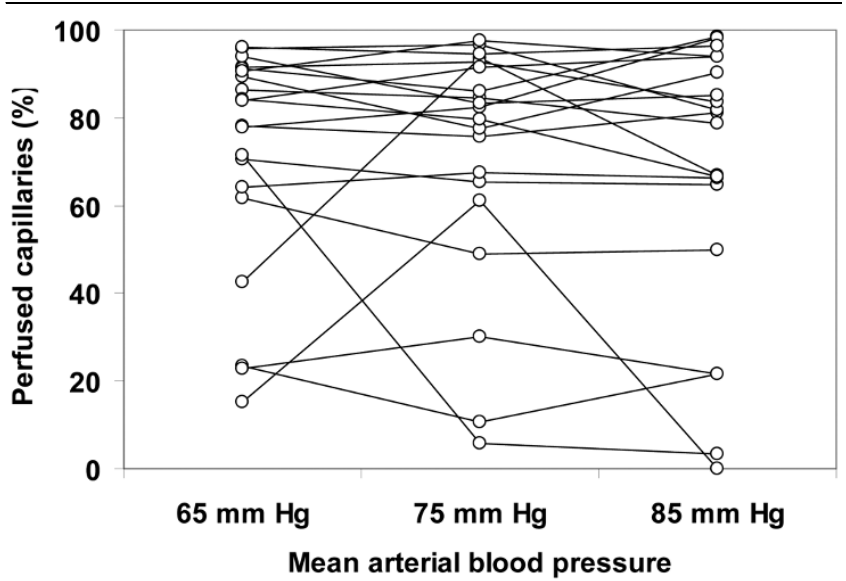

Individual behavior of sublingual percentage of perfused capillaries. Results are shown as the mean arterial pressure was increased from $65 \mathrm{mmHg}$ to $85 \mathrm{mmHg}$ with norepinephrine.

vascular flow and tissue partial pressure of oxygen $\left(\mathrm{PO}_{2}\right)$ without significant changes in sublingual microcirculation [18]. They also showed, however, that when MAP was augmented from 70 to $90 \mathrm{mmHg}$, the $\mathrm{MFI}$, proportion of perfused vessels, and perfused vessel density fell by about $10 \%$. The remarkable similarity between the study by Jhanji and colleagues [18] and the current study emphasizes the reproducibility of the techniques and results.

In addition, our results expand previous knowledge by addressing the variation of interindividual responses. In particular, the change in the perfused capillary density was strongly dependent on the basal state of microcirculation. In this way, perfused capillary density improved in patients with an altered sublingual perfusion at baseline, and decreased in patients

Figure 4

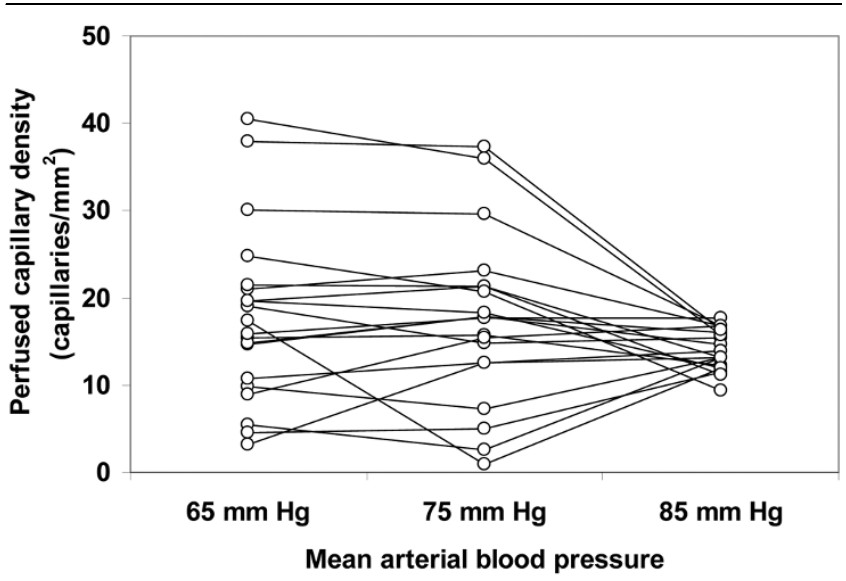

Individual behavior of sublingual perfused capillary density. Results are shown as the mean arterial pressure was increased from $65 \mathrm{mmHg}$ to $85 \mathrm{mmHg}$ with norepinephrine.
Figure 5

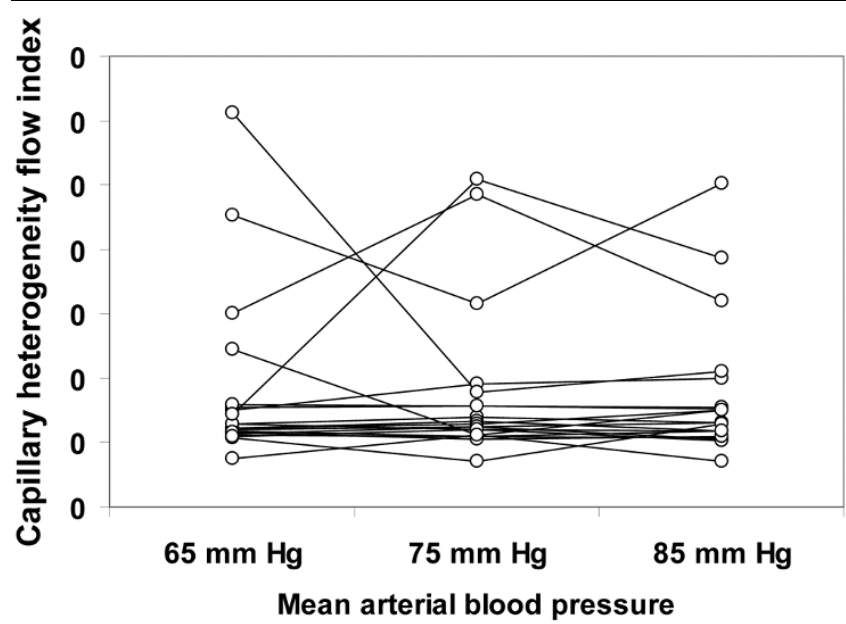

Individual behaviour of sublingual capillary heterogeneity flow index. Results are shown as the mean arterial pressure was increased from $65 \mathrm{mmHg}$ to $85 \mathrm{mmHg}$ with norepinephrine.

with preserved basal microvascular perfusion. Sakr and colleagues described a similar microvascular response to red blood cell transfusion [30]. Other studies have also shown that vasopressors could decrease sublingual microcirculation [31,32], suggesting that excessive vasoconstriction might be deleterious to microcirculation.

Our study has several limitations. First, this observational study lacks a control group. Each patient, therefore, served as his/ her own control. Second, the number of patients included in this study was small. Despite the sample size, significant

\section{Figure 6}

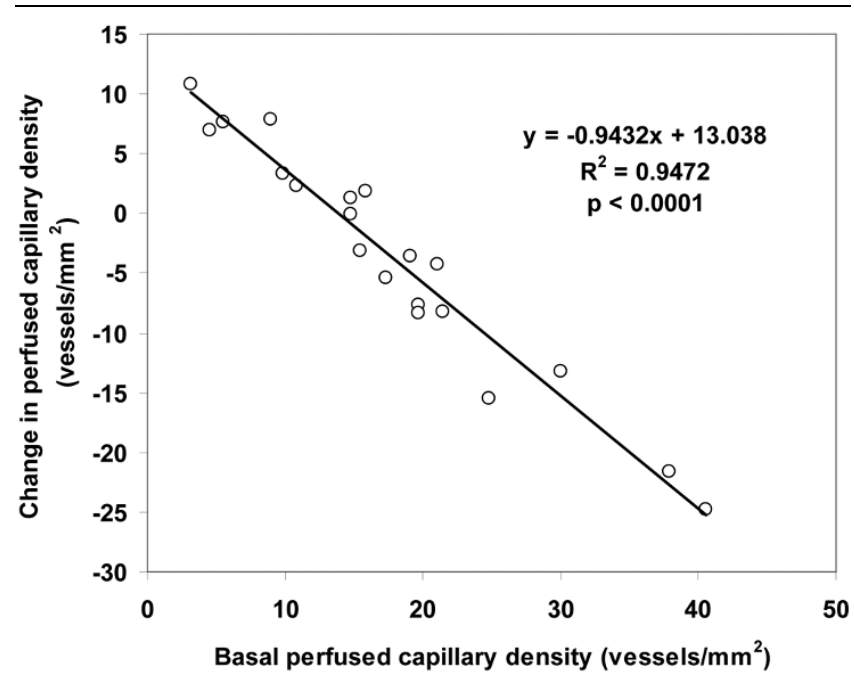

Relationship between the changes of perfused capillary density, when mean arterial pressure (MAP) was increased from the baseline to a MAP of $85 \mathrm{mmHg}$, with the basal perfused capillary density at a MAP of $65 \mathrm{mmHg}$. 
changes in hemodynamic variables developed. Conversely, most parameters related to tissue perfusion and oxygenation remained unchanged or had a trend to worsen. Third, the infusion period was short. A longer period might have allowed the appearance of changes not observed in the present study. Nevertheless, most norepinephrine effects on hemodynamics and on tissue perfusion and oxygenation are expected to be evident within a few minutes. In addition, the short half-life of norepinephrine allows a new steady state to be reached in its plasmatic levels a few minutes after a change in the infusion rate [33]. In fact, several hemodynamic changes appeared shortly after each dose modification. Moreover, the infusion period was deliberately kept short, to avoid the background effects of changes in the underlying conditions of the patients. With longer periods of evaluation, a time effect with spontaneous changes of the studied variables related to the natural history of the disease might not be ruled out. Finally, as a different behaviour of microcirculatory beds is a characteristic of sepsis $[3,34]$, this study does not address the response of other territories to increasing MAP.

\section{Conclusions}

In this observational study, patients with septic shock showed severe microcirculatory alterations that failed to improve with the increases in MAP with norepinephrine. Furthermore, linear trend analysis showed reductions in the capillary and in the perfused capillary densities. Nevertheless, interindividual responses could be quite variable and dependent on the basal state of the microcirculation. Our results suggest that the increase in MAP above $65 \mathrm{mmHg}$ is not a straightforward treatment to improve microvascular perfusion. It might be harmful for some patients, while benefiting others. Studies including greater numbers of patients are needed to determine the usefulness of individual titration of vasopressor therapy on sublingual microcirculation.

\section{Key messages}

- Patients with septic shock showed severe microcirculatory abnormalities that an increase in MAP with norepinephrine globally failed to improve.

- The change in the perfused capillary density was strongly dependent on the basal state of the microcirculation. Thus, perfused capillary density improved in patients with an altered sublingual perfusion at baseline, and decreased in patients with preserved basal microvascular perfusion.

\section{Competing interests}

$\mathrm{Cl}$ is Chief Scientific Officer of MicroVision Medical (a university-based company manufacturing sidestream dark field devices) and holds patents and stock related to SDF imaging. The remaining authors have not disclosed any potential conflicts of interest.

\section{Authors' contributions}

$A D$ designed the study, performed the statistical analysis, and drafted the manuscript. MOP and VSKE were involved in the analysis of the videos. AD, MOP, CAC, FPJr, GM, MCM, and FP made substantial contributions to acquisition of data. EE and $\mathrm{Cl}$ made substantial contributions to analysis and interpretation of data, and were involved in drafting the manuscript and revising it critically for important intellectual content. All authors read and approved the final manuscript.

\section{Acknowledgements}

Supported by the grant PICT-2007-00912, Agencia Nacional de Promoción Científica y Tecnológica, Argentina

\section{References}

1. Landry DW, Oliver JA: The pathogenesis of vasodilatory shock. N Engl J Med 2001, 345:588-595.

2. Ince C: The microcirculation is the motor of sepsis. Crit Care 2005, 9 Suppl 4:S13-S19.

3. Dubin A, Edul VS, Pozo MO, Murias G, Canullán CM, Martins EF, Ferrara G, Canales HS, Laporte M, Estenssoro E, Ince C: Persistent villi hypoperfusion explains intramucosal acidosis in sheep endotoxemia. Crit Care Med 2008, 36:535-542.

4. De Backer D, Creteur J, Preiser JC, Dubois MJ, Vincent JL: Microvascular blood flow is altered in patients with sepsis. $A m \mathrm{~J}$ Respir Crit Care Med 2002, 166:98-104.

5. Sakr Y, Dubois MJ, De Backer D, Creteur J, Vincent JL: Persistent microcirculatory alterations are associated with organ failure and death in patients with septic shock. Crit Care Med 2004, 32:1825-1831.

6. De Backer D, Creteur J, Dubois MJ, Sakr Y, Koch M, Verdant C, Vincent JL: The effects of dobutamine on microcirculatory alterations in patients with septic shock are independent of its systemic effects. Crit Care Med 2006, 34:403-408.

7. Spronk PE, Ince C, Gardien MJ, Mathura KR, Oudemans-van Straaten HM, Zandstra DF: Nitroglycerin in septic shock after intravascular volume resuscitation. Lancet 2002 360:1395-1396.

8. Johnson PC: Autoregulation of blood flow. Circ Res 1986, 59:483-495.

9. Avontuur JA, Bruining HA, Ince C: Nitric oxide causes dysfunction of coronary autoregulation in endotoxemic rats. Cardiovasc Res 1997, 35:368-376.

10. Terborg C, Schummer W, Albrecht M, Reinhart K, Weiller C, Röther J: Dysfunction of vasomotor reactivity in severe sepsis and septic shock. Intensive Care Med 2001, 27:1231-1234.

11. LeDoux D, Astiz ME, Carpati CM, Rackow EC: Effects of perfusion pressure on tissue perfusion in septic shock. Crit Care Med 2000, 28:2729-2732.

12. Bourgoin A, Leone M, Delmas $A$, Garnier F, Albanèse J, Martin C: Increasing mean arterial pressure in patients with septic shock: effects on oxygen variables and renal function. Crit Care Med 2005, 33:780-786.

13. Zhang $\mathrm{H}$, Smail N, Cabral A, Rogiers $P$, Vincent JL: Effects of norepinephrine on regional blood flow and oxygen extraction capabilities during endotoxic shock. Am J Respir Crit Care Med 1997, 155:1965-1971.

14. Bellomo R, Kellum JA, Wisniewski SR, Pinsky MR: Effects of norepinephrine on the renal vasculature in normal and endotoxemic dogs. Am J Respir Crit Care Med 1999, 159:1186-1192.

15. Regueira T, Bänziger B, Djafarzadeh S, Brandt S, Gorrasi J, Takala J, Lepper PM, Jakob SM: Norepinephrine to increase blood pressure in endotoxaemic pigs is associated with improved hepatic mitochondrial respiration. Crit Care 2008, 12:R88.

16. Krouzecky A, Matejovic M, Radej J, Rokyta R Jr, Novak I: Perfusion pressure manipulation in porcine sepsis: effects on intestinal hemodynamics. Physiol Res 2006, 55:527-533.

17. Treggiari MM, Romand JA, Burgener D, Suter PM, Aneman A: Effect of increasing norepinephrine dosage on regional blood 
flow in a porcine model of endotoxin shock. Crit Care Med 2002, 30:1334-1339.

18. Jhanji S, Stirling S, Patel N, Hinds CJ, Pearse RM: The effect of increasing doses of norepinephrine on tissue oxygenation and microvascular flow in patients with septic shock. Crit Care Med 2009, 37:1961-1966.

19. American College of Chest Physicians/Society of Critical Care Medicine Consensus Conference: definitions for sepsis and organ failure and guidelines for the use of innovative therapies in sepsis. Crit Care Med 1992, 20:864-874.

20. Figge J, Jabor A, Kazda A, Fencl V: Anion gap and hypoproteinemia. Crit Care Med 1998, 26:1807-1810.

21. Goedhart PT, Khalilzada M, Bezemer R, Merza J, Ince C: Sidestream Dark Field (SDF) imaging: a novel stroboscopic LED ring-based imaging modality for clinical assessment of the microcirculation. Optics Express 2007, 15:15101-15114.

22. Boerma EC, Mathura KR, van der Voort PH, Spronk PE, Ince C: Quantifying bedside-derived imaging of microcirculatory abnormalities in septic patients: a prospective validation study. Crit Care 2005, 9:R601-R606.

23. Trzeciak S, Dellinger RP, Parrillo JE, Guglielmi M, Bajaj J, Abate NL, Arnold RC, Colilla S, Zanotti S, Hollenberg SM, Microcirculatory Alterations in Resuscitation and Shock Investigators: Early microcirculatory perfusion derangements in patients with severe sepsis and septic shock: relationship to hemodynamics, oxygen transport, and survival. Ann Emerg Med 2007, 49:88-98.

24. De Backer D, Hollenberg S, Boerma C, Goedhart P, Büchele G, Ospina-Tascon G, Dobbe I, Ince C: How to evaluate the microcirculation: report of a round table conference. Crit Care 2007, 11:R101.

25. Bewick V, iz Cheek L, Ball J: Statistics review 9: One-way analysis of variance. Critical Care 2004, 8:130-136.

26. Marik PE, Mohedin M: The contrasting effects of dopamine and norepinephrine on systemic and splanchnic oxygen utilization in hyperdynamic sepsis. JAMA 1994, 272:1354-137.

27. Martin C, Eon B, Saux P, Aknin P, Gouin F: Renal effects of norepinephrine used to treat septic shock. Crit Care Med 1990, 18:282-285.

28. Desjars $P$, Pinaud M, Bugnon D, Tasseau F: Norepinephrine therapy has no deleterious renal effects in human septic shock. Crit Care Med 1989, 17:426-429.

29. Deruddre S, Cheisson G, Mazoit JX, Vicaut E, Benhamou D, Duranteau J: Renal arterial resistance in septic shock: effects of increasing mean arterial pressure with norepinephrine on the renal resistive index assessed with Doppler ultrasonography. Intensive Care Med 2007, 33:1557-1562.

30. Sakr Y, Chierego M, Piagnerelli M, Verdant C, Dubois MJ, Koch M, Creteur J, Gullo A, Vincent JL, De Backer D: Microvascular response to red blood cell transfusion in patients with severe sepsis. Crit Care Med 2007, 35:1639-1644.

31. Maier S, Hasibeder WR, Hengl C, Pajk W, Schwarz B, Margreiter $\mathrm{J}$, Ulmer $\mathrm{H}$, Engl J, Knotzer $\mathrm{H}$ : Effects of phenylephrine on the sublingual microcirculation during cardiopulmonary bypass. Br J Anaesth 2009, 102:485-491.

32. Boerma EC, Voort PH van der, Ince C: Sublingual microcirculatory flow is impaired by the vasopressin-analogue terlipressin in a patient with catecholamine-resistant septic shock. Acta Anaesthesiol Scand 2005, 49:1387-1390.

33. Beloeil H, Mazoit JX, Benhamou D, Duranteau J: Norepinephrine kinetics and dynamics in septic shock and trauma patients. $\mathrm{Br}$ $J$ Anaesth 2005, 95:782-788.

34. Boerma EC, Voort PH van der, Spronk PE, Ince C: Relationship between sublingual and intestinal microcirculatory perfusion in patients with abdominal sepsis. Crit Care Med 2007, 35:1055-1060. 